\title{
Permanent Magnet Synchronous Motor Drive Based on Modified Space Vector Pulse Width Modulation
}

\author{
Prof. Dr. Basil M. Saied \\ bmsaied@gmail.com \\ Electrical Engineering Department \\ Laith A. Mohammed \\ University of Mosul \\ Mosul - Iraq
}

\begin{abstract}
The paper introduces a modified space vector pulse width modulation strategy which has been used to drive and control the speed of permanent magnet synchronous motor. This strategy, compared with relative conventional SVPWM method, has important features. Such features are increasing the utilization of DC link input voltage of the inverter, reducing the stress on power switching devices, and therefore minimizing the switching losses. The proposed approach is analyzed and simulated. Also a complete system model of the permanent magnet synchronous motor (PMSM) drive, using MatLab-Simulink, has been performed. The obtained results, for conventional and modified approaches, have been compared. In order to verify the theoretical results, practical test has been performed which shows that the proposed technique is preferable than the conventional type.
\end{abstract}

Keyword: PMSM, d-q modeling, AC drive, VSI, SVPWM.
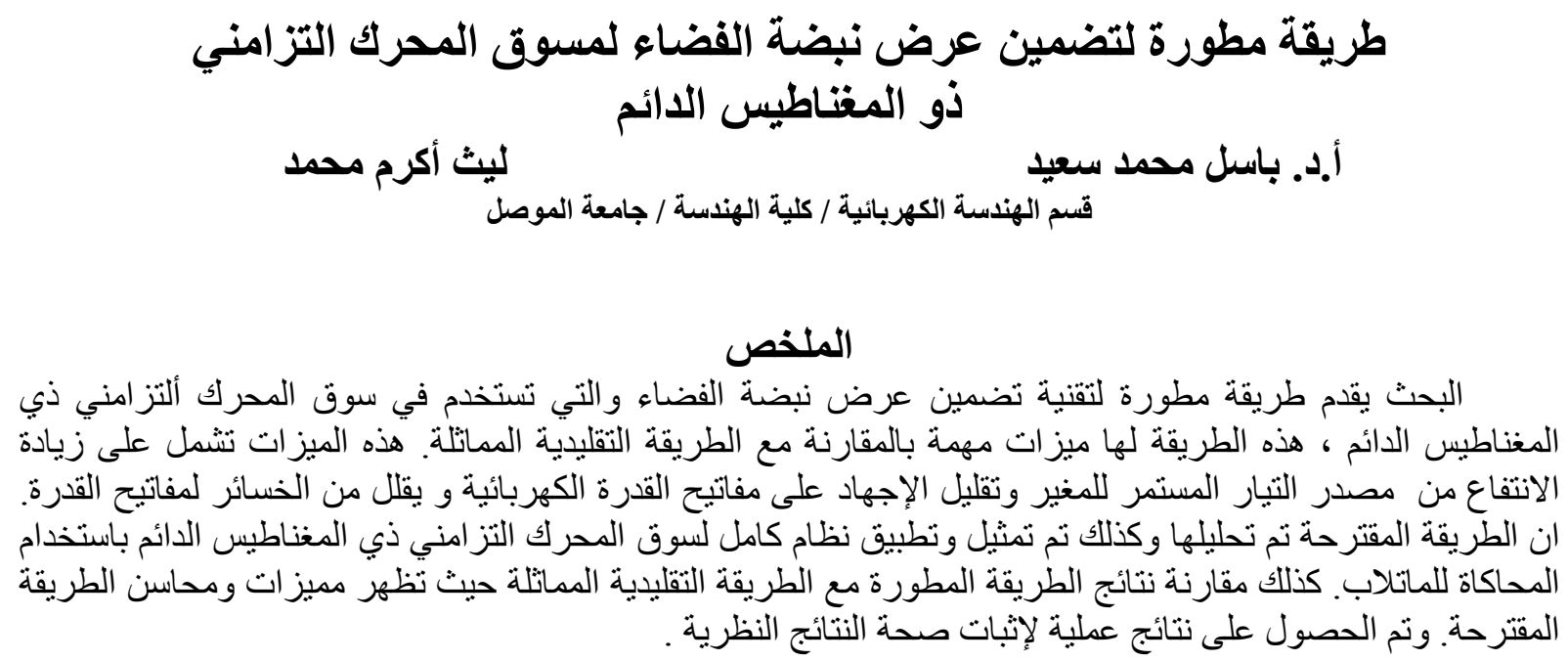

Received: 19 - 6 - 2013

Accepted: 2 - 10 - 2013 

Al-Rafidain Engineering
Vol.22
No. 4
May 2014

\section{1-Introduction}

Recently permanent magnet synchronous motor (PMSM) has been widely used in various applications due to its merits and features. Such applications are drive motion control, electrical vehicles and tractions. The rotor of PMSM has permanent magnet, therefore negligible power loss, higher efficiency ,compact size and low weight compared with other types of synchronous motors. Also a highest torque to-weight ratio is achievable with high efficiency particularly when using rotor with PM type Neodymium Iron Boride-NeFeB[1,2]. Two types of PM synchronous machines were used for applications requiring a wide speed range of constant-power operation. Key observations include: surface permanent magnet synchronous machines (SPMSM) and interior permanent magnet synchronous machines (IPMSM)can both be designed to achieve wide speed ranges of constant-power operation[2]. SPMSM with fractional-slot concentrated windings offer opportunities to minimize machine volume and mass because of their short windings. While the IPMSM, also known as salient type, which has many advantages like high speed, small size and good dynamic response. In general PMSM has a sinusoidal back emf and requires sinusoidal stator currents to produce constant torque. PMSM is very similar to the conventional wound rotor synchronous machine, except that the PMSM has constant field provided by a permanent magnet. A generalized-circuit theory approach permits a direct solution of all kinds of steady state and transient electrical circuit conditions[3]. Due to simplicity many researches deal with d-q model (park transformation ) of the PMSM [4].They have introduced modeling, using different PWM strategies to drive, system of PMSM based on MatLab-Simulink. Building of simulation system was discussed in detail. Dynamic modeling and simulation for many types such as ac SPMSM with the aid of MatLab-Simulink environment had been proposed[5,6]. Other they produced a Precise modeling of PMSM that considered the nonlinear characteristics of the hard and soft magnetic materials used in the machine [7]. The space vector pulse width modulation (SVPWM) strategy produces a high utilization of DC input voltage, compared with other types of PWM strategies such as sinusoidal pulse width modulation (SPWM). Also in order to reduce the total harmonic distortion, the switching frequency must be increased. This will cause an increase of the stress and switching energy loss of the power devices as well as increase the electromagnetic interference (EMI).Therefore this paper propose a strategy to modify space vector pulse width modulation (MSVPWM) as a contribution to improve the performance of PMSM.

\section{2-Permanent Magnet Synchronous Motor Model}

The mathematical model for the PMSM is similar to the model of a wound rotor type synchronous machine, except that the field assumed constant. Using park's transformation, PMSM is usually modeled in the rotor reference frame [48].The vector graph of PMSM is shown in Fig.(1).

Where $i_{\text {sd }}$ and $i_{\text {sq }}$ are $d-q$ axes stator currents , $\psi_{\mathrm{f}}$ is the flux linkage due to permanent magnet and $\delta$ is the load angle.

The following assumptions are taken into account when representing the PMSM model[5,6]:

1 -Saturation is neglected.

2-The back emf is assumed sinusoidal.

3-The eddy current and hysteresis losses are ignored.

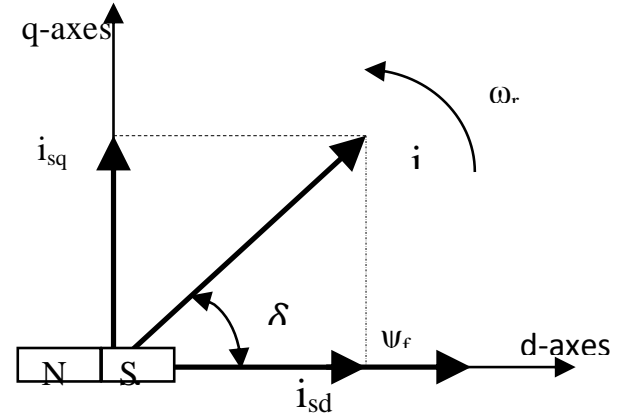

Fig. (1): The vector graph of a synchronous motor with permanent magnet 
The transformation from three -phase to two phase time variant $\alpha \beta$ elements in a fixed reference frame by using Clarke transformations:

$\left[\begin{array}{l}I_{\alpha} \\ I_{\beta}\end{array}\right]=\frac{2}{3}\left[\begin{array}{ccc}1 & -\frac{1}{2} & -\frac{1}{2} \\ 0 & \frac{\sqrt{3}}{2} & -\frac{\sqrt{3}}{2}\end{array}\right] \cdot\left[\begin{array}{l}I_{a} \\ I_{b} \\ I_{c}\end{array}\right]$

While the transformation from two stationary axes to rotating axes, by using Park transformation, is:

$\left[\begin{array}{l}I_{d} \\ I_{q}\end{array}\right]=\left[\begin{array}{cc}\cos \theta & \sin \theta \\ -\sin \theta & \cos \theta\end{array}\right] \cdot\left[\begin{array}{c}I_{\alpha} \\ I_{\beta}\end{array}\right]$

Where $\theta$ is the angle between d-axis and $\alpha$-axis as shown in Fig.(2)

$\mathrm{V}_{\mathrm{d}}$ and $\mathrm{V}_{\mathrm{q}}$ are obtained directly from $\mathrm{V}_{\mathrm{a}}, \mathrm{V}_{\mathrm{b}}$ and $\mathrm{V}_{\mathrm{c}}$ through park's transformation as follows:-

$\left[\begin{array}{l}V_{q} \\ V_{d} \\ V_{0}\end{array}\right]=\frac{2}{3}\left[\begin{array}{ccc}\cos \theta & \cos \left(\theta-\frac{2 \pi}{3}\right) & \cos \left(\theta+\frac{2 \pi}{3}\right) \\ \sin \theta & \sin \left(\theta-\frac{2 \pi}{3}\right) & \sin \left(\theta+\frac{2 \pi}{3}\right) \\ 1 / 2 & 1 / 2 & 1 / 2\end{array}\right]\left[\begin{array}{c}V_{a} \\ V_{b} \\ V_{c}\end{array}\right]$

The direct and quadrant voltage equations are:

$\mathrm{V}_{\mathrm{d}}=\mathrm{RI}_{\mathrm{d}}+\rho \lambda_{\mathrm{d}}-\omega_{\mathrm{r}} \lambda_{\mathrm{q}}$

(4)

$\mathrm{V}_{\mathrm{q}}=\mathrm{RI}_{\mathrm{q}}+\rho \lambda_{\mathrm{q}}+\omega_{\mathrm{r}} \lambda_{\mathrm{d}}$

(5)

Where $\mathrm{R}$ is stator winding resistance in ohm and $\omega_{r}$ is the

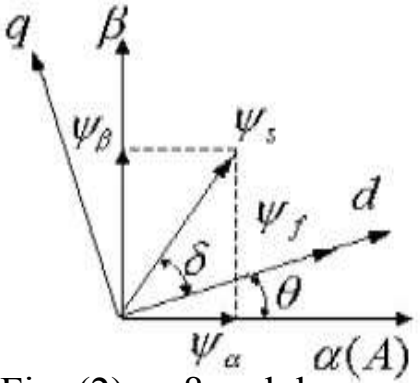

Fig. (2): $\alpha-\beta$ and $d-q$ axes rotor electrical speed in $\mathrm{rad} / \mathrm{sec}$.

$\lambda_{\mathrm{q}}=\mathrm{L}_{\mathrm{q}} \mathrm{I}_{\mathrm{q}}$

$\lambda_{\mathrm{d}}=\mathrm{L}_{\mathrm{d}} \mathrm{I}_{\mathrm{d}}+\psi_{\mathrm{f}}$

Where $\psi_{\mathrm{f}}$ is the flux linkage due to the rotor magnets linking the stator and $\rho=\mathrm{d} / \mathrm{dt}$.

$\lambda_{\mathrm{d}}$ and $\lambda_{\mathrm{q}}$ are flux linkage with respect to $\mathrm{d}, \mathrm{q}$ axes respectively, $\mathrm{L}_{\mathrm{d}}$ and $\mathrm{L}_{\mathrm{q}}$ are self-inductance for $\mathrm{d}$, $\mathrm{q}$ axes respectively. $\mathrm{I}_{\mathrm{d}}$ and $\mathrm{I}_{\mathrm{q}}$ are $\mathrm{d}$, $\mathrm{q}$-currents respectively.

The developed electromagnetic torque is given by[1-7]:

$\mathrm{Te}=\frac{3}{2}\left(\frac{\mathrm{p}}{2}\right)\left[\psi_{f} \mathrm{I}_{\mathrm{q}}+\left(\mathrm{L}_{\mathrm{d}}-\mathrm{L}_{\mathrm{q}}\right) \mathrm{I}_{\mathrm{d}} \mathrm{I}_{\mathrm{q}}\right]$

Where $\mathrm{P}$ is the machine pole number.

The general dynamic torque equation for the machine is:

$\mathrm{T}_{\mathrm{e}}=\mathrm{T}_{\mathrm{L}}+\mathrm{B} \omega_{\mathrm{m}}+\mathrm{J} \rho \omega_{\mathrm{m}}$

Where $T_{L}$ is the load torque (N.m), B is the viscous friction coefficient N.m/(rad/sec), J is the moment of inertia of the machine $\left(\mathrm{kg} . \mathrm{m}^{2}\right)$, and $\omega_{\mathrm{m}}$ is the rotor mechanical $\operatorname{speed}\left(\omega_{\mathrm{m}}=\omega_{\mathrm{r}}-\frac{2}{P}\right)$ in rad per sec.

The rotor speed can be obtained from equation (9) as :

$\omega_{\mathrm{m}}=\int\left(\frac{\mathrm{Te}-\mathrm{TL}-\mathrm{B} \omega_{\mathrm{m}}}{J}\right) d t$

The PM motor drive simulation system has been built in several steps like ABC phase transformation to dqo variables, and calculation of torque and speed. Fig(3) shows the MatLab-Simulink Model of the PMSM . 

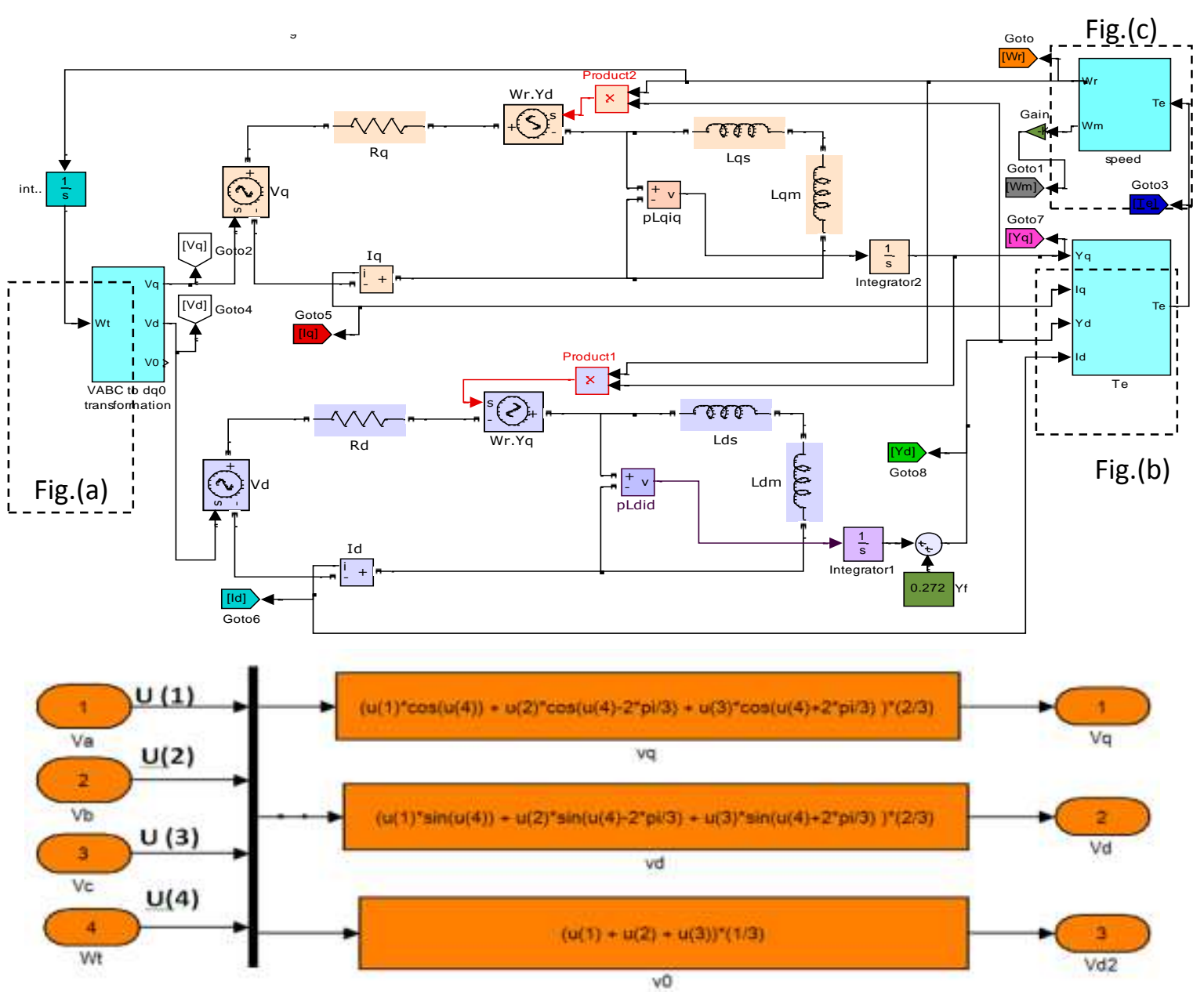

Fig. (a) ABC to d-q Transformation
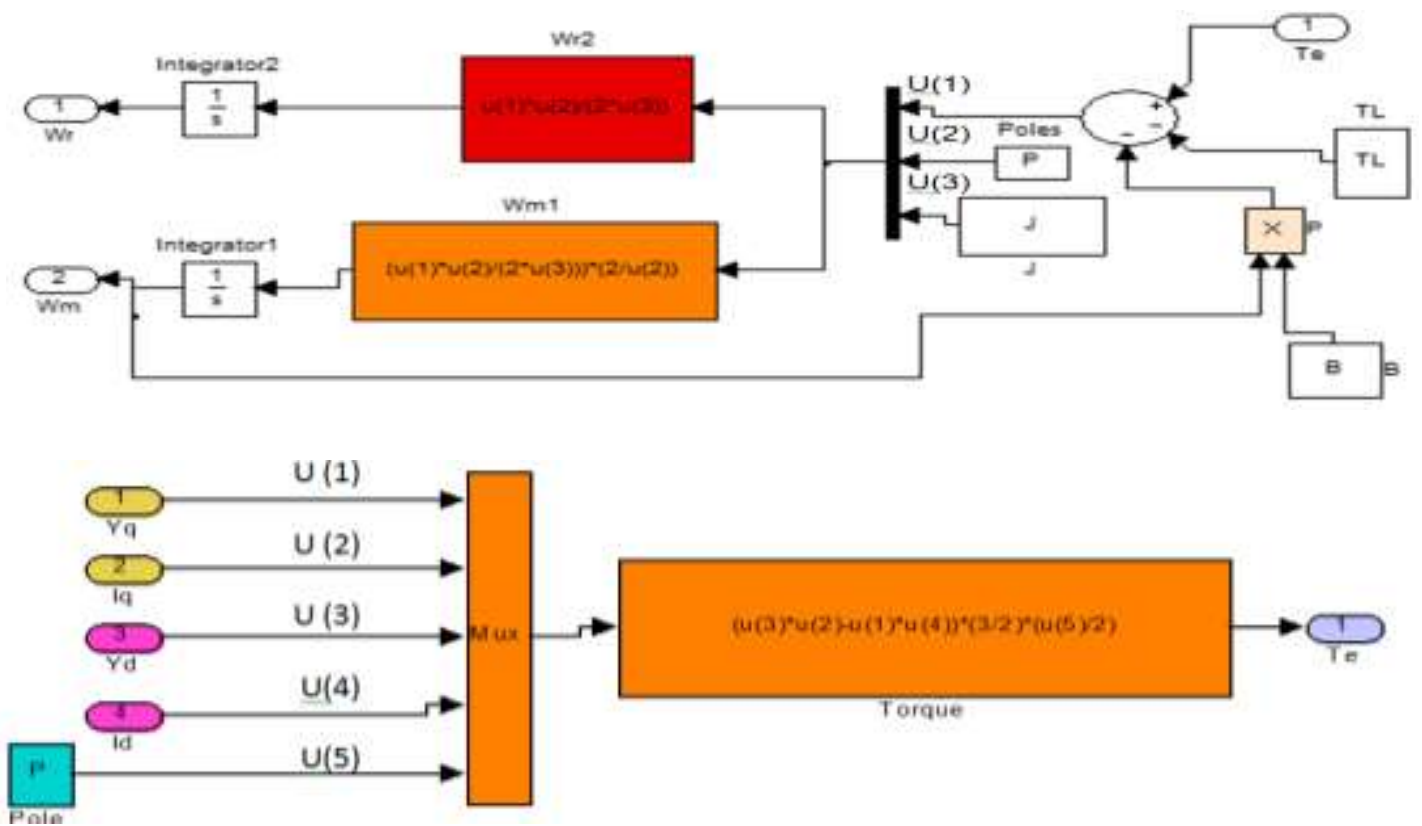

Fig.(c): Mechanical and electrical speed

Fig. (3): Space vector pulse width modulation PMSM drive model 


\section{3-Space Vector Pulse Width Modulation Approach}

Space vector pulse width modulation (SVPWM) is one of the most popular techniques which is widely used by industrial application due to its feature, such as its control strategy can be implemented in digital system and has efficient utilization of dc bus compared with other PWM strategies[9,10]. The theory of space vector is based on representing three-phase system $V_{a}(t), V_{b}(t)$ and $V_{c}(t)$ by a rotating vector $V_{r}$ :

$\mathrm{V}_{\mathrm{r}}=\frac{2}{3}\left[\mathrm{~V}_{\mathrm{a}}(\mathrm{t})+\mathrm{a} * \mathrm{~V}_{\mathrm{b}}(\mathrm{t})+\mathrm{a}^{2} * \mathrm{~V}_{\mathrm{c}}(\mathrm{t})\right]$

Where $\mathrm{a}=1 e^{j \frac{2}{3} \pi}, \mathrm{a}^{2}=1 e^{j \frac{4}{3} \pi}$

A six pulse voltage source inverter, is shown in Fig.(4), has eight permissible switching states $2^{3}=8$, the switching states a , b , c, $\mathrm{a}^{\prime}, \mathrm{b}^{\prime}$ and $\mathrm{c}^{\prime}$ can be represented as logic ' 1 ' when the switches in ON state and ' 0 ' when the switches in OFF state. The pair a a ', b b' and c c' are complementary to avoid short circuit across the dc link[9].

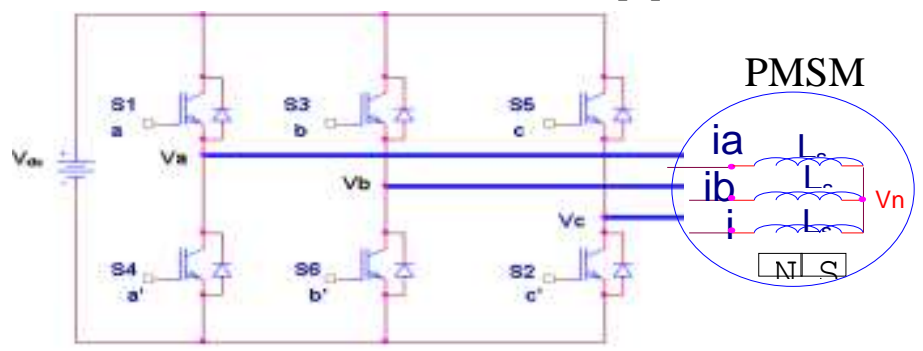

Fig. (4): Three phase voltage source inverter

The line and phase voltage can be calculated as follows:

$$
\begin{aligned}
& {\left[\begin{array}{l}
\mathrm{V}_{\mathrm{ab}} \\
\mathrm{V}_{\mathrm{bc}} \\
\mathrm{V}_{\mathrm{ca}}
\end{array}\right]=\mathrm{V}_{\mathrm{dc}}\left[\begin{array}{lrr}
1 & -1 & 0 \\
\mathrm{O} & 1 & -1 \\
-1 & 0 & 1
\end{array}\right]\left[\begin{array}{l}
\mathrm{a} \\
\mathbf{b} \\
\mathrm{c}
\end{array}\right]} \\
& {\left[\begin{array}{l}
\mathrm{V}_{\mathrm{an}} \\
\mathrm{V}_{\mathrm{bn}} \\
\mathrm{V}_{\mathrm{cn}}
\end{array}\right]=\frac{2}{3} \mathrm{~V}_{\mathrm{dc}}\left[\begin{array}{crr}
1 & -\frac{1}{2} & -\frac{1}{2} \\
-\frac{1}{2} & 1 & -\frac{1}{2} \\
-\frac{1}{2} & -\frac{1}{2} & 1
\end{array}\right]\left[\begin{array}{l}
\mathrm{a} \\
\mathrm{b} \\
\mathrm{c}
\end{array}\right]}
\end{aligned}
$$

Where $\left[\begin{array}{lll}a & b & c\end{array}\right]^{t}$ is the transpose matrix of the switching variable vectors. The eight possible state vectors for six step inverter are summarized in Fig. (5). 

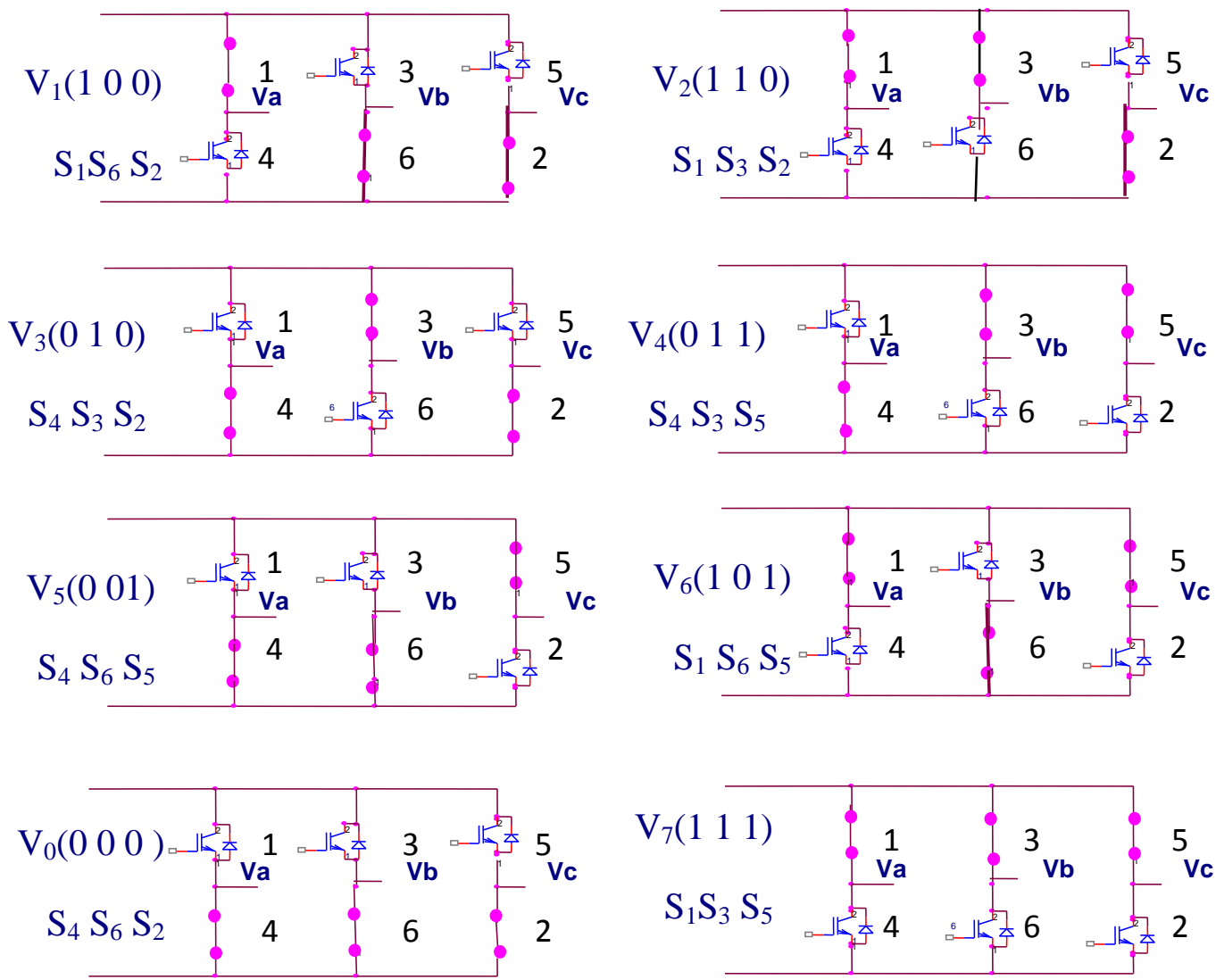

Fig. (5): Eight inverter voltage vector for six step voltage source inverter

The six-switches combinations in the inverter have eight permissible switching states. The active vectors $\left(\mathrm{V}_{1} \ldots \mathrm{V}_{6}\right)$ can be represented by the axes of hexagonal that has the magnitude of $2 / 3 \mathrm{Vdc}$ and the angle between any two adjacent vectors equals to $\pi / 3$ radians and the non-active vectors $\left(\mathrm{V}_{0}\right.$ and $\left.\mathrm{V}_{7}\right)$ at the origin as shown in Fig.(6) [9-11]. The space vector, according to the equivalence principle, the following operation rules are obtained: $\mathrm{V}_{1}=-\mathrm{V}_{4}, \mathrm{~V}_{2}=-\mathrm{V}_{5}, \mathrm{~V}_{3}=-\mathrm{V}_{6}$ and $\mathrm{V}_{0}=\mathrm{V}_{7}=0$.

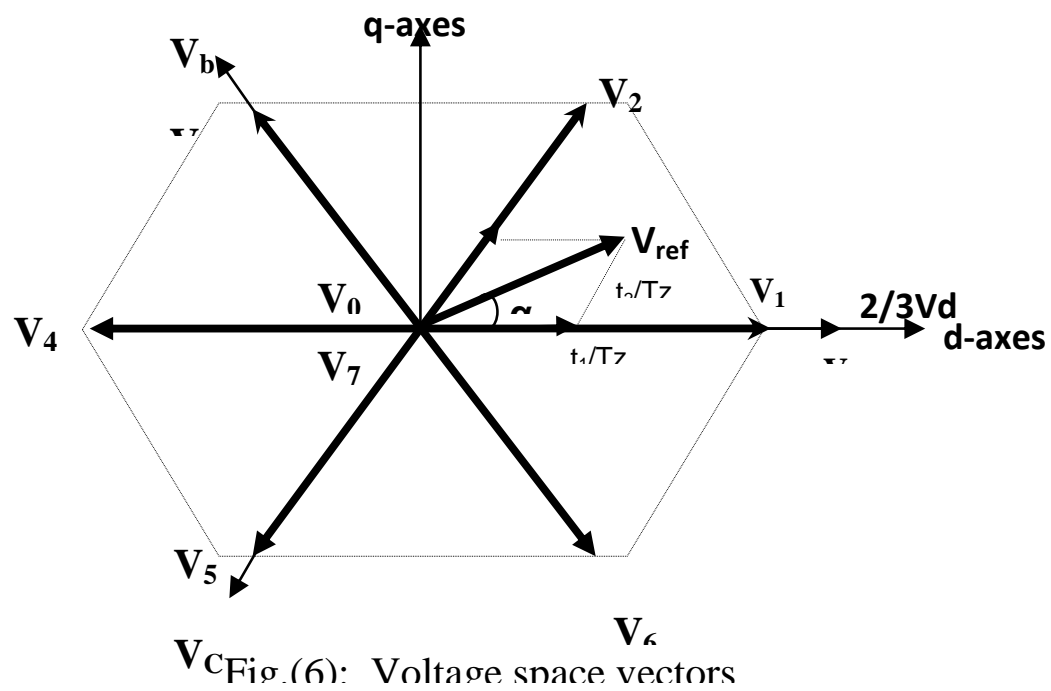


The desired three phase voltages $\mathrm{V}_{\mathrm{an}}, \mathrm{V}_{\mathrm{bn}}$ and $\mathrm{V}_{\mathrm{cn}}$ at the load of the inverter can be represented by an equivalent reference vector $V_{\text {ref }}$ which has magnitude of the output voltage rotating in the counter clock wise direction and the period of the fundamental output voltage is equal to the one complete revolution of the reference vector $\mathrm{V}_{\text {ref. }}$.

As an example in one sampling interval the output vector

$\overline{\mathrm{V}}_{\text {ref }}=\frac{\mathrm{t} 0}{\mathrm{Tz}} \overline{\mathrm{V}}_{0}+\frac{\mathrm{t} 1}{\mathrm{Tz}} \overline{\mathrm{V}}_{1}+\cdots+\frac{\mathrm{t} 7}{\mathrm{Tz}} \overline{\mathrm{V}}_{7}$

Where $t_{0}, t_{1} \ldots t_{7}$ are the ON sharing times of all the vectors $\bar{V}_{0}, \bar{V}_{1} \ldots . \bar{V}_{7}$, and Tz is the complete sampling period. Eqn.(14)represents the decomposition of $\overline{\mathrm{V}}_{\text {ref }}$ into $\overline{\mathrm{V}}_{0}, \overline{\mathrm{V}}_{1} \ldots \overline{\mathrm{V}}_{7}$ has infinite ways [11]. To make full use of $\mathrm{ON}$ times for active vectors, the reference vector splits in two nearest adjacent active vectors and two non-active vectors. For example if the reference vector is in sector 1 for one sampling interval $\mathrm{Tz}$ and with angle $\alpha$ along $\mathrm{d}$-axes as shown in $\operatorname{Fig}(6)$, then the relation between $d-q$ axes voltage $V_{d}$ and $V_{q}$ with phase load voltage $\mathrm{V}_{\mathrm{an}}, \mathrm{V}_{\mathrm{bn}}$ and $\mathrm{V}_{\mathrm{cn}}$

$\therefore\left[\begin{array}{c}\mathrm{V}_{\mathrm{d}} \\ \mathrm{V}_{\mathrm{q}}\end{array}\right]=\frac{2}{3}\left[\begin{array}{ccc}1 & -\frac{1}{2} & -\frac{1}{2} \\ 0 & \frac{\sqrt{3}}{2} & -\frac{\sqrt{3}}{2}\end{array}\right]\left[\begin{array}{c}\mathrm{V}_{\mathrm{an}} \\ \mathrm{V}_{\mathrm{bn}} \\ \mathrm{V}_{\mathrm{cn}}\end{array}\right]$

Where $\quad \alpha=\tan ^{-1}\left(\frac{\mathrm{V}_{\mathrm{q}}}{\mathrm{V}_{\mathrm{d}}}\right)$ and $\left|\overline{\mathrm{V}}_{\mathrm{ref}}\right|=\sqrt{\mathrm{V}_{\mathrm{d}}{ }^{2}+\mathrm{V}_{\mathrm{q}}{ }^{2}}$

To generate sinusoidal line to line output voltage, the reference vector transitions smoothly between sectors with small interval time (sampling period).

Fig.(7) shows the SVPWM with six samples per sector and the total number of samples equal to 36 , that's mean the switching frequency $f s=36 * f_{o}$, where $f_{o}$ is fundamental frequency. The angles $60>\alpha_{6}>\alpha_{5}>\alpha_{4}>\alpha_{3}>$ $\alpha_{2}>\alpha_{1}>0$. Tz is the sampling period of the given circular locus[9]. As the number of samples increases, the locus of transition reference vector will be circular and the total harmonic distortion decreases but it results of increasing the switching loss and stress on power switches. The pattern of each switch of the inverter is the sum of each sample interval which depends on the active and non-active times of the vectors. $\alpha_{1}, \alpha_{2} \ldots, \alpha_{36}$, determine the active and nonactive times of each sample according to related sector where

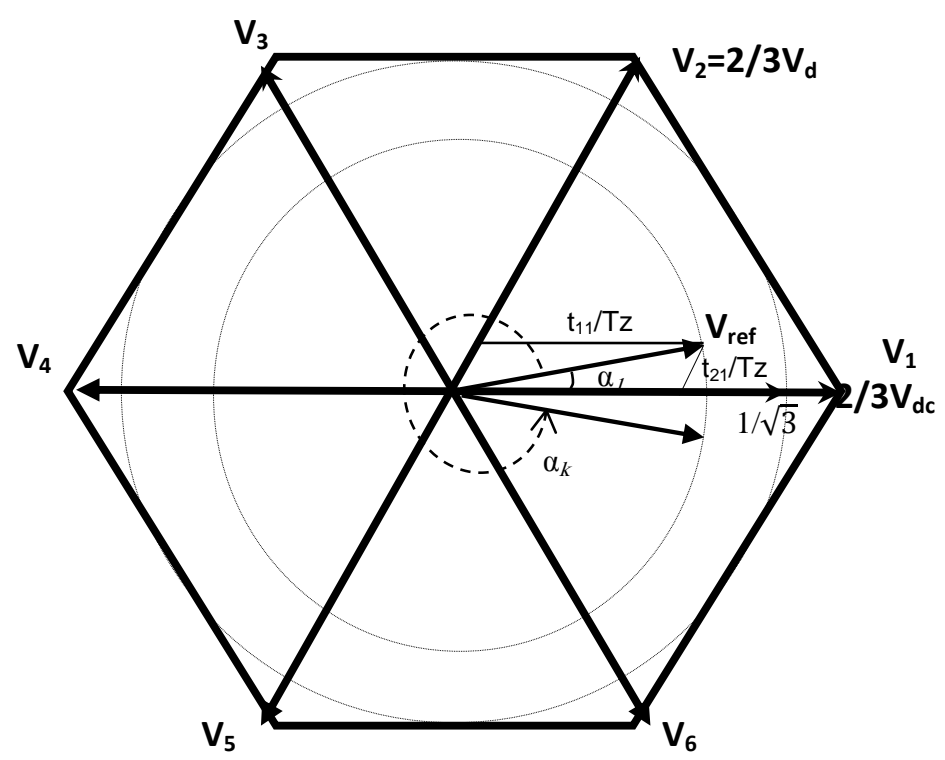

Fig. (7): Voltage space vectors with $\mathrm{f}_{\mathrm{s}}=36^{*} \mathrm{f}_{\mathrm{o}}$ 
$: 0 \leq \alpha \leq 60$ sector $1,60 \leq \alpha \leq 120 \quad$ sector $2,120 \leq \alpha \leq 180$ sector $3,180 \leq \alpha \leq 240$ sector $4,240 \leq \alpha \leq 300$ sector 5 , and $300 \leq \alpha \leq 360$ sector 6 .

Keeping in mind the maximum length of the active vectors $\left(2 / 3 \mathrm{~V}_{\mathrm{dc}}\right)$, while the locus of the reference vector is a circle and the maximum reference value is equal to $1 / \sqrt{ } 3 \mathrm{~V}_{\mathrm{dc}}$, which represents the radius of outer circle as given in Fig.(7). This means that the maximum value of modulation index $\mathrm{M}$ in linear region is equal to $\left(1 / \sqrt{ } 3 \mathrm{~V}_{\mathrm{dc}}\right) /\left(2 / 3 \mathrm{~V}_{\mathrm{dc}}\right)=0.866$.

\subsection{Space Vector Switching Pattern:}

This paper is trying to reduce the switching frequency per fundamental period for, any certain number of samples. This is performed by distributing the switching sequence in such a way that the transition from one state to the next is performed by switching only one inverter leg at a time[9]. The only remaining degree of freedom consists in the way that sharing ' $t_{0}{ }^{\prime}$ between the vectors $\mathrm{V}_{0}, \mathrm{~V}_{7}$.

To determine the active and non-active duration times formula, it is referred to Fig.(6). The values of $\mathrm{V} 1$ and $\mathrm{V}_{2}$ are constant, while $\mathrm{V}_{0}=\mathrm{V}_{7}=0$. The volt-time of reference voltage $\mathrm{V}_{\text {ref }}$ to the space vector is obtained as follows:

$$
\begin{aligned}
& \bar{V}_{r e f} \cdot T z=\bar{V}_{1} \cdot t_{1}+\bar{V}_{2} \cdot t_{2}+t_{0} \cdot\left(\bar{V}_{0} \text { or } \bar{V}_{7}\right) \\
& \bar{V}_{r e f}=\bar{V}_{1} \cdot \frac{t_{1}}{T z}+\bar{V}_{2} \cdot \frac{t_{2}}{T z}+\frac{t_{0}}{T z} \cdot\left(\bar{V}_{0} \text { or } \bar{V}_{7}\right)
\end{aligned}
$$

By converting $\bar{V}_{\text {ref }}, \bar{V}_{1}$ and $\bar{V}_{2}$ along d-q-axes result

$$
\begin{aligned}
& \left|\overline{\mathrm{V}}_{\text {ref }}\right| \cdot\left[\begin{array}{c}
\cos (\alpha) \\
\sin (\alpha)
\end{array}\right]=\frac{\mathrm{t}_{1}}{T z} \cdot \frac{2}{3} \cdot \mathrm{V}_{\mathrm{dc}} \cdot\left[\begin{array}{l}
1 \\
0
\end{array}\right]+\frac{\mathrm{t}_{2}}{T z} \cdot \frac{2}{3} \cdot \mathrm{V}_{\mathrm{dc}} \cdot\left[\begin{array}{c}
\cos (\pi / 3) \\
\sin (\pi / 3)
\end{array}\right] \\
& \quad\left(\text { where, } 0 \leq \alpha \leq 60^{\circ}\right) \\
& \text { Then } \quad t_{1}=T_{z} \cdot M \cdot \frac{\sin (\pi / 3-\alpha)}{\sin (\pi / 3)}, t_{2}=T_{z} \cdot M \cdot \frac{\sin (\alpha)}{\sin (\pi / 3)} \\
& \therefore t_{0}=T_{z}-\left(t_{1}+t_{2}\right)
\end{aligned}
$$

And the switching time duration for active and non-active vector time in any sector:

$$
\begin{aligned}
& t_{1 i}=T_{z} \cdot M \cdot \frac{\sin \left(\pi / 3-\left(\alpha_{i}-n \times \frac{\pi}{3}\right)\right)}{\sin (\pi / 3)} \\
& t_{2 i}=T_{z} \cdot M \cdot \frac{\sin \left(\alpha_{i}-n \times \frac{\pi}{3}\right)}{\sin (\pi / 3)}
\end{aligned}
$$

where $\mathrm{n}=1$ through 6 (no. of sectors) and $\mathrm{i}=(1$ through $\mathrm{k})$

$\mathrm{k}=$ total number of samples $=\mathrm{fs} / \mathrm{f}_{\mathrm{o}}$ and $\mathrm{M}=$ Modulation index $=\frac{\left|V_{r e f}\right|}{\frac{2}{3} V_{d c}}$ 
For linear modulation region $\mathrm{M}=(0-0.866)$, the symmetric method to generate space vector sequence in order to reduce the stress on power switches is prefer [8], which has equal sharing of the zero vector intervals on each sampling interval, as an example the reference voltage fall in sector (1) $\mathrm{V}_{0}, \mathrm{~V}_{1}, \mathrm{~V}_{2}, \mathrm{~V}_{7}, \mathrm{~V}_{7}, \mathrm{~V}_{2}, \mathrm{~V}_{1}, \mathrm{~V}_{0}$. Fig.(8) shows the switching patterns for reference vector in sector 1. Table (1) shows the corresponding pulse width for each switch in each sector.

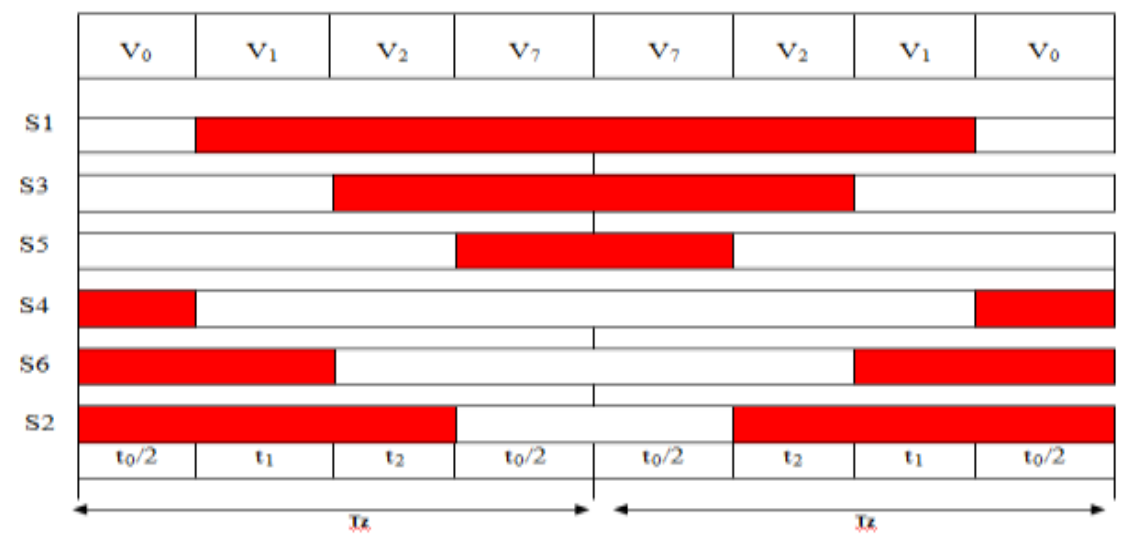

Fig. (8): Switching pattern for reference vector in sector 1

Table (1) The switching time for each sector

\begin{tabular}{||c||c|c|c|c|c|c||}
\hline $\begin{array}{c}\text { Switch } \\
\text { No. }\end{array}$ & Sector 1 & Sector 2 & Sector 3 & Sector 4 & Sector 5 & Sector 6 \\
\hline S1 & $\mathrm{t}_{1}+\mathrm{t}_{2}+\mathrm{t}_{0} / 2$ & $\mathrm{t}_{1}+\mathrm{t}_{0} / 2$ & $\mathrm{t}_{0} / 2$ & $\mathrm{t}_{0} / 2$ & $\mathrm{t}_{2}+\mathrm{t}_{0} / 2$ & $\mathrm{t}_{1}+\mathrm{t}_{2}+\mathrm{t}_{0} / 2$ \\
\hline $\mathrm{S} 4$ & $\mathrm{t}_{0} / 2$ & $\mathrm{t}_{2}+\mathrm{t}_{0} / 2$ & $\mathrm{t}_{1}+\mathrm{t}_{2}+\mathrm{t}_{0} / 2$ & $\mathrm{t}_{1}+\mathrm{t}_{2}+\mathrm{t}_{0} / 2$ & $\mathrm{t}_{1}+\mathrm{t}_{0} / 2$ & $\mathrm{t}_{0} / 2$ \\
\hline $\mathrm{S} 3$ & $\mathrm{t}_{2}+\mathrm{t}_{0} / 2$ & $\mathrm{t}_{1}+\mathrm{t}_{2}+\mathrm{t}_{0} / 2$ & $\mathrm{t}_{1}+\mathrm{t}_{2}+\mathrm{t}_{0} / 2$ & $\mathrm{t}_{1}+\mathrm{t}_{0} / 2$ & $\mathrm{t}_{0} / 2$ & $\mathrm{t}_{0} / 2$ \\
\hline $\mathrm{S} 6$ & $\mathrm{t}_{1}+\mathrm{t}_{0} / 2$ & $\mathrm{t}_{0} / 2$ & $\mathrm{t}_{0} / 2$ & $\mathrm{t}_{2}+\mathrm{t}_{0} / 2$ & $\mathrm{t}_{1}+\mathrm{t}_{2}+\mathrm{t}_{0} / 2$ & $\mathrm{t}_{1}+\mathrm{t}_{2}+\mathrm{t}_{0} / 2$ \\
\hline $\mathrm{S} 5$ & $\mathrm{t}_{0} / 2$ & $\mathrm{t}_{0} / 2$ & $\mathrm{t}_{2}+\mathrm{t}_{0} / 2$ & $\mathrm{t}_{1}+\mathrm{t}_{2}+\mathrm{t}_{0} / 2$ & $\mathrm{t}_{1}+\mathrm{t}_{2}+\mathrm{t}_{0} / 2$ & $\mathrm{t}_{1}+\mathrm{t}_{0} / 2$ \\
\hline $\mathrm{S} 2$ & $\mathrm{t}_{1}+\mathrm{t}_{2}+\mathrm{t}_{0} / 2$ & $\mathrm{t}_{1}+\mathrm{t}_{2}+\mathrm{t}_{0} / 2$ & $\mathrm{t}_{1}+\mathrm{t}_{0} / 2$ & $\mathrm{t}_{0} / 2$ & $\mathrm{t}_{0} / 2$ & $\mathrm{t}_{2}+\mathrm{t}_{0} / 2$ \\
\hline
\end{tabular}

\subsection{Modified Space Vector Pulse Width Modulation MSVPWM}

When the modulation index M of SVPWM is greater than 0.8 and sampling number is relatively high, some of notches between pulses are small with respect to sampling period $T_{z}$, this means the pulse width of the sample is equal to $\left(t_{1}+t_{2}+t_{0} / 2\right)$ and the notch ' $t_{0} / 2$ ' is relatively very small, compared with $\mathrm{T}_{\mathrm{z}}$. Therefore the effect of notch ' $\mathrm{t}_{0} / 2$ ' is eliminated by considering no change in switching state of the power to reduce the switching losses and the stress on the power switches. If the sampling frequency is multiple of six (or 12,18,24...) the total number of eliminated notches can be calculated according to $\mathrm{N}_{\text {notch }}=2 * \mathrm{~N}$ where $\mathrm{N}$ is the total number of samples in one sector and the resultant number of pulse $=\mathrm{W}_{\mathrm{f}}-\mathrm{N}_{\text {notch }}+1$ where $\mathrm{W}_{\mathrm{f}}$ is frequency ratio $=\mathrm{f}_{\mathrm{s}} / \mathrm{f}_{\mathrm{o}}$ and the same value of total harmonic distortion for output current waveform can be obtained by eliminating these notches.

\section{4-Simulation Results}

A PMSM used in the model has the following parameters specifications : $(1.1 \mathrm{KW}$, $\mathrm{R}=6.34 \Omega, 340 \mathrm{~V}, \mathrm{~L}_{\mathrm{d}}=89 \mathrm{mH}, \mathrm{L}_{\mathrm{q}}=65 \mathrm{mH}, \lambda_{\mathrm{f}}=0.8 \mathrm{wb}$.turn, $\mathrm{I}$ rated $=2.85 \mathrm{~A}$ and $\mathrm{T}_{\mathrm{L}}=7 \mathrm{~N} . \mathrm{m}$ ) and the SVPWM voltage source inverter used to drive the PMSM use sampling frequency $=1800 \mathrm{~Hz}$, and $M=0.85$. Using MatLab the results are shown in Figs.( 9-11).Fig. (9a\&b) shows PWM patterns to drive Transistor S1 based on SVPWM and MSVPWM methods respectively. The switching frequency is reduced from $1800 \mathrm{~Hz}$ to $1250 \mathrm{~Hz}$. Fig. $(10-\mathrm{a} \& \mathrm{~b})$ shows the motor line voltage, with their spectrums, for SVPWM and MSVPWM respectively. As seen from the 
spectrums they are almost same. This means that the switching frequency is reduced by $31 \%$ while THD is almost same. Also the dc utilization is improved by $5 \%$. Similarly, with Fig. $(11-a \& b)$ and Fig (12-a\&b), the motor line currents and their spectrums, torque and speed waveforms, for both SVPWM and MSVPWM respectively are almost the same.

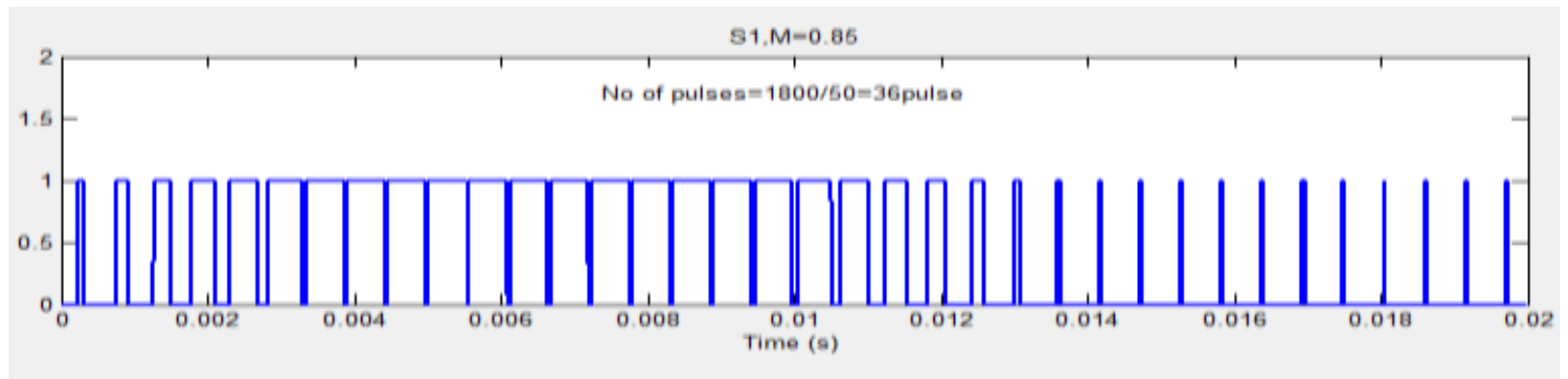

a)

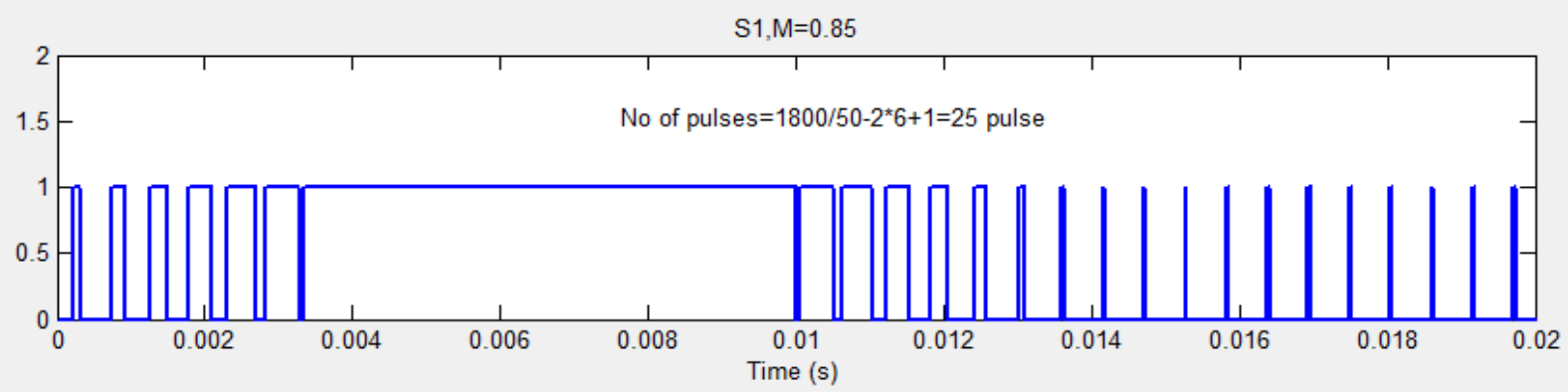

b)

Fig. (9): Switch S1 pattern a) SVPWM b) MSPWM

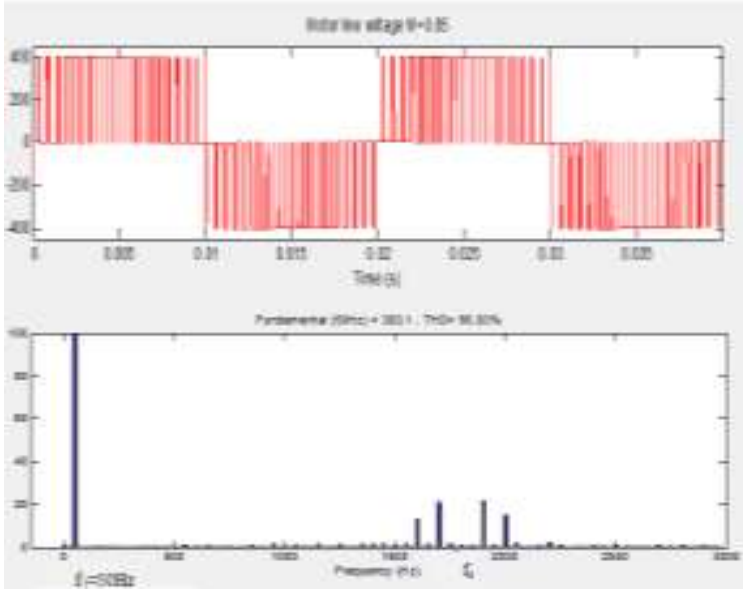

a)

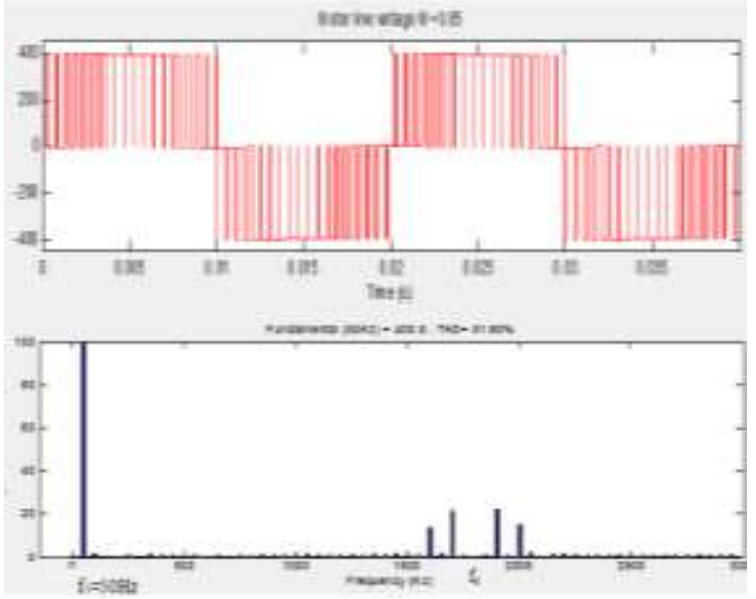

b)

Fig. (10): Motor line voltage a) SVPWM .b) MSPWM 

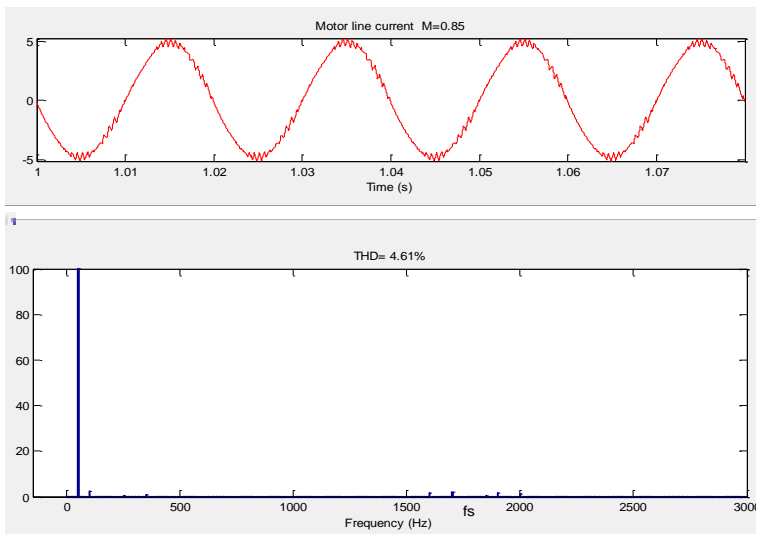

a)

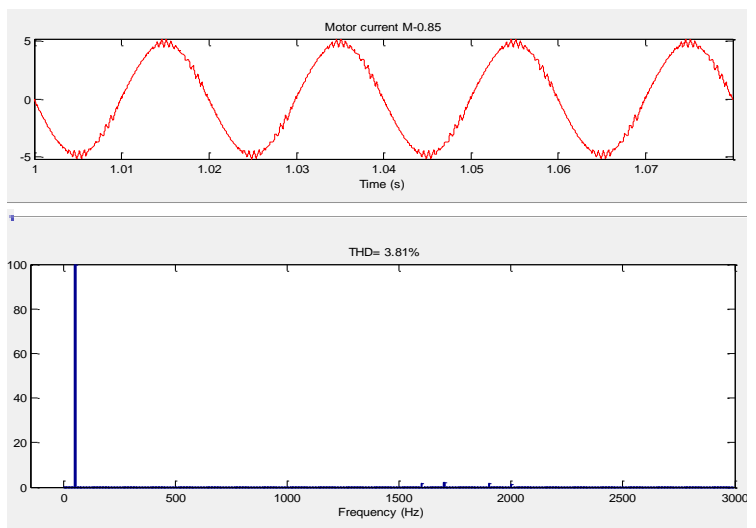

b)

Fig. (11): Motor current a) SVPWM b) MVSPWM

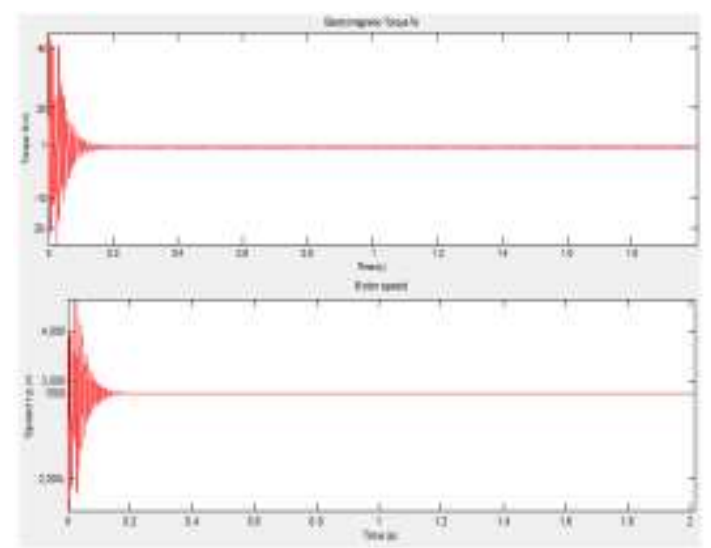

a)

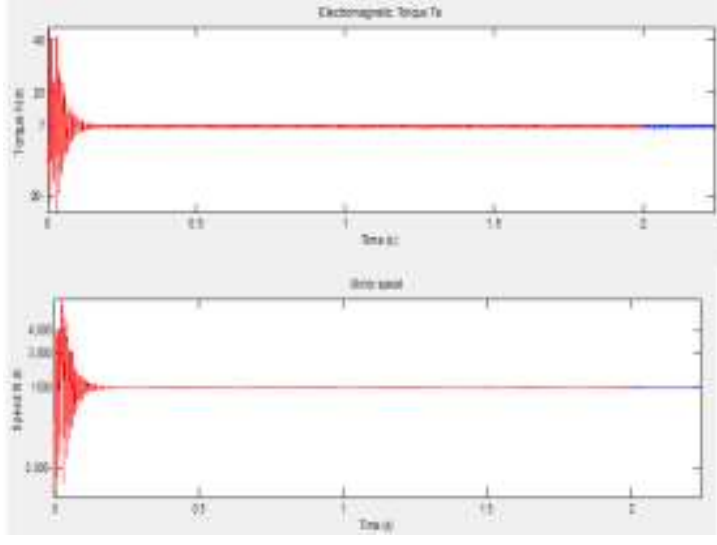

b)

Fig. (12): Motor speed and Torque a) SVPWM b) MVSPWM

\section{5-Practical Results}

To verify the simulation results, practical results have been obtained, using dSPACE 7.4. The real time of PWM pattern to drive the power transistor $\left(S_{1}\right)$ and inverter terminal voltage waveform with its spectrum, based on SVPWM approach, are shown in Fig. (13a,b\&c). Similar, for MSVPWM approach are shown in Fig.(14-a,b\&c). The above practical results show that the proposed method can be efficiently used to reduce the switching frequency, which reduces significantly the switching losses and improving the performance of PMSM drive system. Also the dc link voltage is highly utilized. 


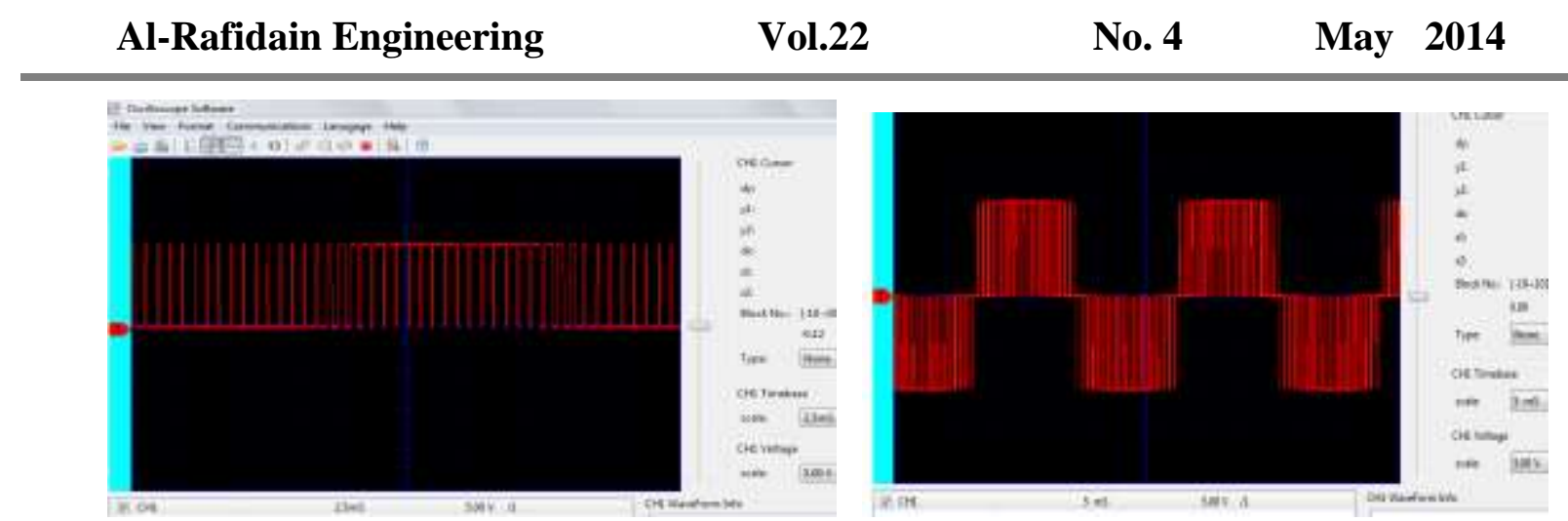

b)

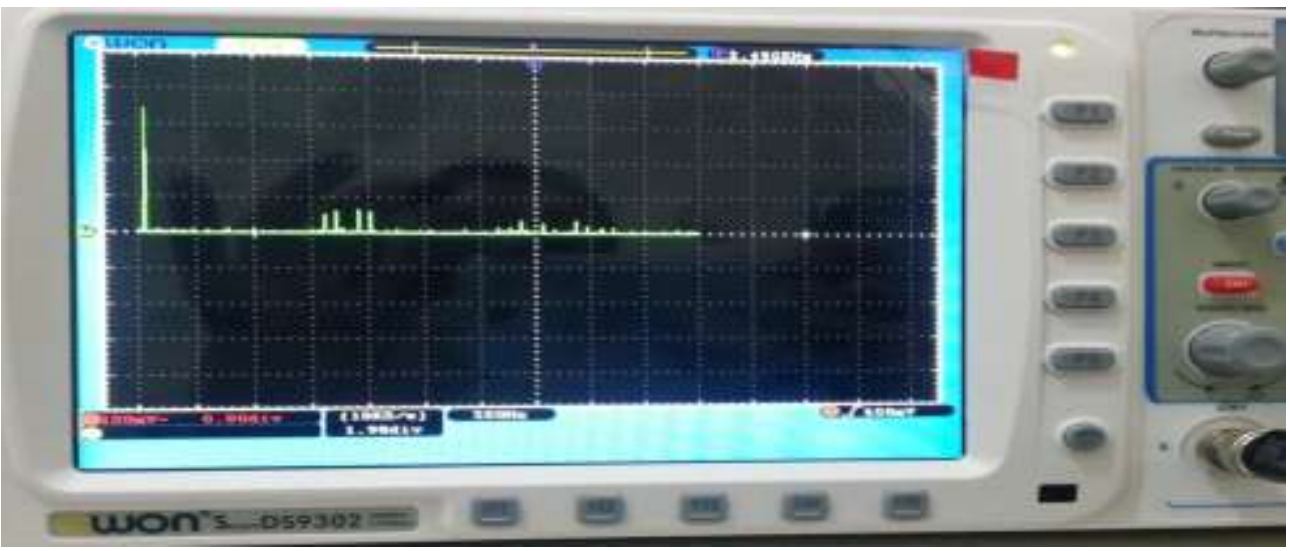

c)

Fig. (13): a) Power switch pattern. b) Line voltage .c) Spectrum of line voltage

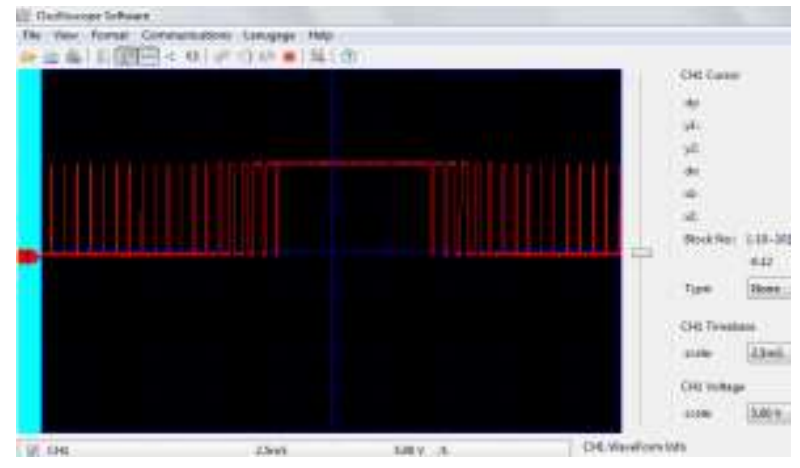

a)

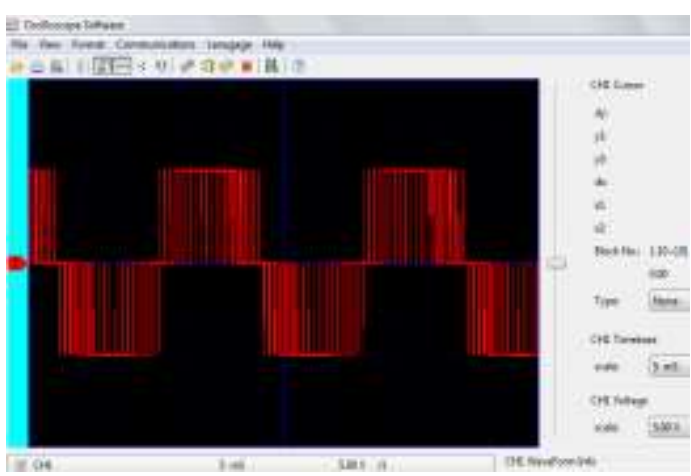

b)

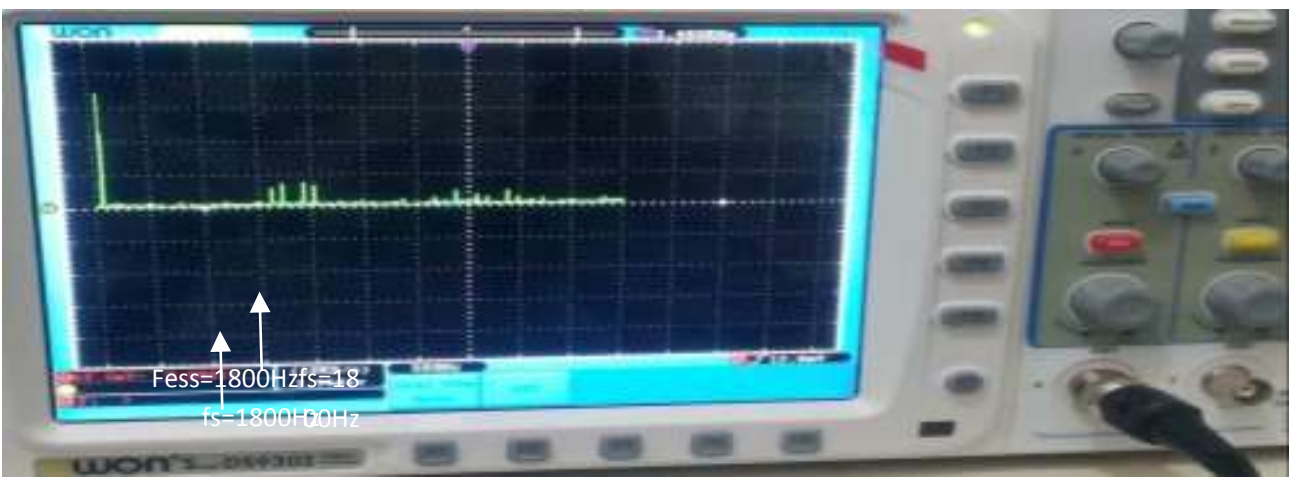

c)

Fig.(14): a) power switch pattern. b) line voltage .c) spectrum of line voltage 


\section{Conclusion}

In this paper a modeling approach for PMSM based on park's Transformations has been derived. The modeling procedures have been presented and simulation results are obtained such as; speed ,torque, stator voltage and stator current using MATLAB-Simulink. The theory of the Space Vector pulse width modulation for a 3-phase inverter has been presented. A proposed MSVPWM is introduced by eliminating the small notching of the pulses. According to the obtained results, which are performed for wide range of the modulation index, it can be concluded that the width of small notches are reduced as modulation index increases. Therefore these notches are relatively very small with respect to sampling period $\mathrm{Tz}$, at $\mathrm{M}=0.85$ the ratio of minimum pulse width with respect to sampling period $\left(\mathrm{t}_{0} / 2 / \mathrm{Tz}\right)$ vary from $(4.6 \%-0.2 \%)$ which is small compared with other pulses and can be eliminated .The proposed method confirms the following features; reduces the switching frequency, reduces the stress on power switching devices, reduces EMI, improves the efficiency, increases the utilization of dc link source, and minimizes the susceptibility of fault for the complementary of the power transistors. For typical case, when $\mathrm{M}=0.85, \mathrm{Vdc}=400 \mathrm{~V}$, the fundamental output line voltage equal to $383.1 \mathrm{~V}(270.9 \mathrm{Vrms})$ when the switching frequency $\mathrm{f}_{\mathrm{s}}=1800 \mathrm{~Hz}$, no. of pulses $=36$ for SVPWM while the fundamental output line voltage equal to $400.8 \mathrm{~V}(283.5 \mathrm{Vrms})$ at $\mathrm{f}_{\mathrm{s}}=1250 \mathrm{~Hz}$,no. of pulses $=25$ for MSVPWM. The practical results shows that the same harmonic component in the line voltage spectrum for both SVPWM and MSVPWM approaches, because the most significant harmonic components depend on sampling frequency, $1800 \mathrm{~Hz}$, which are assumed same for comparison .

\section{References}

[1] Tomaz Rudricki and AleKsander Frechowiz,"Permanent magnet Synchronous Motor Control Driver", international conference Mixed design of integrated circuits and systems, Jun. 16-18, 2011, pp. 545-547.

[2] Enrique L. Carrillo Arroyo, "Modeling and Simulation of Permanent Magnet Synchronous Motor Drive System", M.Sc. Thesis, University of Puterto Rico, 2006.

[3] John Hindmarsh,"Electrical Machines and Their applications ", $4^{\text {th }}$ edition 1984, p. 687

[4] Zhuqiang Lu, Honggang Sheng and Herbert L. Hess ,"The Modeling and Simulation of a Permanent Magnet Synchronous Motor with Direct Torque Control Based on Matlab/ Simulink IEEE" 2005, pp.1150-1156.

[5] Adel El Shahat and Hamed El Shewy, "Permanent Magnet Synchronous Motor Dynamic Modeling with Genetic Algorithm", International Journal of Engineering, Science and Technology 2010, Vol. 2, No. 2, pp. 93-106.

[6] Pragasn Pillay and, Andr. Krishnan, "Modeling of Permanent Magnet Motor Drives", IEEE Transactions on Industrial Electronics, Vol. 35, No.4, November 1988, pp.537-541.

[7] Markus Seilmeier and Bernhard Piepenbreier, "Modeling of PMSM with multiple saliencies using a stator-oriented magnetic circuit approach "IEEE international Electric Machine and Drives conference, 2011, pp.131-136.

[8] P. Krause, "Analysis of Electric Machinery". New York: McGraw- Hill, 1986.

[9] Dorin O. Neacsu "Space Vector Modulation-An Introduction" The $27^{\text {th }}$ Annual Conference of the IEEE Industrial Electronics Society, 2001, pp. 1583- 1592.

[10] R. Arulmozhiyal, K. Baskaran, "Space Vector Pulse Width Modulation Based Speed Control of Induction Motor using Fuzzy PI Controller", International Journal of Computer and Electrical Engineering, Vol. 1, No. 1, April 2009, pp. 98-103. 
[11] Keliang Zhou and Danwei Wang "Relationship Between Space-Vector Modulation and Three-Phase Carrier-Based PWM:A Comprehensive Analysis "IEEE Transactions on Industrial Electronics, Vol. 49, No. 1, February 2002, pp. 186-195.

[12] Muhamed H. Rashid "Power electronics circuits, Devices and applications", $3^{\text {rd }}$ Edition 2004 , p. 862.

[13] Bimal K. Bose "Power Electronics and Motor Drives", 2006.

[14] E. Hendawi, F. Khater, A. Shaltout " Analysis, Simulation and Implementation of Space Vector Pulse Width Modulation Inverter "Proceedings of the $9^{\text {th }}$ WSEAS International Conference on Applications of Electrical Engineering, Penang, Malaysia, March 23-25, 2010, pp. $124-131$. 